\title{
Research on vibration employed for the train traffic control
}

\author{
Rafal Burdzik ${ }^{1}$, Lukasz Konieczny $^{2}$, Bogusław Nowak ${ }^{3}$, Jacek Rozmus ${ }^{4}$ \\ ${ }^{1,2}$ Silesian University of Technology, Faculty of Transport, 40-019, Katowice, Poland \\ ${ }^{3,4}$ DR-TECH Sp. z. o.o., 41-407, Imielin, Poland \\ ${ }^{1}$ Corresponding author \\ E-mail: ${ }^{1}$ rafal.burdzik@polsl.pl, ${ }^{2}$ lukasz.konieczny@polsl.pl, ${ }^{3}$ boguslaw@drtech.pl,,jacek@drtech.pl
}

Received 26 September 2017; accepted 5 October 2017

DOI https://doi.org/10.21595/vp.2017.19237

Check for updates

\begin{abstract}
The paper presents extended abstract on preliminary research on vibration employed for the trains traffic control. The research was conducted on experimental rail track with typical level crossing devices. The results present 3-axle distribution of vibration generated by the train simulator wheel-rail contact. For the sake of the numerical analysis of magnitude of the vibration the basic statistics have been calculated. The Fourier transformations of the signals presents the dominant frequency bands.
\end{abstract}

Keywords: rail vibration, level crossing, train traffic control.

\section{Introduction}

The train traffic control system must be able to handle heavy frequent traffic and higher speeds. Passive level crossings are often upgraded with active controls such as flashing red lights. Traffic signals may provide good safety outcomes at level crossings but remain untested [1]. Traffic of trains on the railway infrastructure are regulated through a signaling system and a well-defined set of rules. One of the most important components of railway safety system is train detection systems. The signaling devices are usually triggered by sensors by trains approaching the crossing level and which are in the impact area of heads of the wheel sensors detecting movement in their area and movement direction of the rail vehicle. There are following warning devices installed at the crossings: light traffic control devices most frequently with a sound signal and one or two pairs of half barriers.

From the point of view of transport safety in the widest sense, in terms of transport by rail, the most important and at the same time the most critical point of the infrastructure are road-rail level crossings. Thus, intersection of the railway system with the road transport system, through rail level crossings represents one key area of railway transport safety research. Some researchers are focused on driver behaviour at railway crossings as the major collision factor [1-3]. At the same time there are many publications on railway safety in aspect of infrastructure, system and devices.

The traditional system is based on light signals separating portion of tracks called block sections. Crossing signaling devices are triggered by the train approaching the mentioned crossing by track-side sensors. There are following warning devices installed at the crossings: light traffic control devices most frequently with a sound signal so called bell and one or two pairs of half barriers. Triggering of the crossing takes place several dozen seconds before the nose of the train reaches the crossing and turning off few seconds after the last axle left the crossing. Railway signaling facilitates two main functions, namely, train detection and train control, in order to maintain safe separations among the trains. Track circuits are the most commonly used train detection means with the simple open/close circuit principles and subsequent adoption of axle counters further allows the detection of trains under adverse track conditions [4]. However, with electrification and power electronics traction drive systems, aggravated by the electromagnetic interference in the vicinity of the signaling system, railway engineers often find unstable or even faulty operations of track circuits and axle counting systems [4].

The Japanese railway uses Automatic Train Control system (ATC) devices that display the permitted speed and apply braking automatically in accordance with the emerging instruction on 
high speed line sections and high density lines. The ATC on-ground equipment transmits signal currents for controlling speeds in track circuits and the on-board ATC equipment receives these signals [5]. The paper [4] presents a novel optical fiber sensor signaling system. Axle counting by FBG sensors is based on measuring the strain changes in the rail upon the passage of trains at the measurement points.

In the previous publications Authors have assumed that for the improving of railway crossing safety level the support system for the vehicle passage identification can be developed. Some preliminary conception has been depicted in [6]. Thus, the investigation has been performed on application of vibration wave propagation employing as source of information. Also, some other conceptions for acquiring information about the approaching vehicle have been analysed but these will be subject of further publications.

The emission of vibration includes the vehicle-track-soil interaction, the vehicle and track irregularities, and the dynamic axle loads. [8]. The rail provides the contact between the train wheel and the track. Vibrations from trains propagating from the rail to the ballast go through the sleepers, strainings these elements [9]. The profile irregularity of a railway line is one of the essential vibration sources for vehicles and track (Fig. 1). With a high number of trains, the properties of the track amplify the excitation [10].

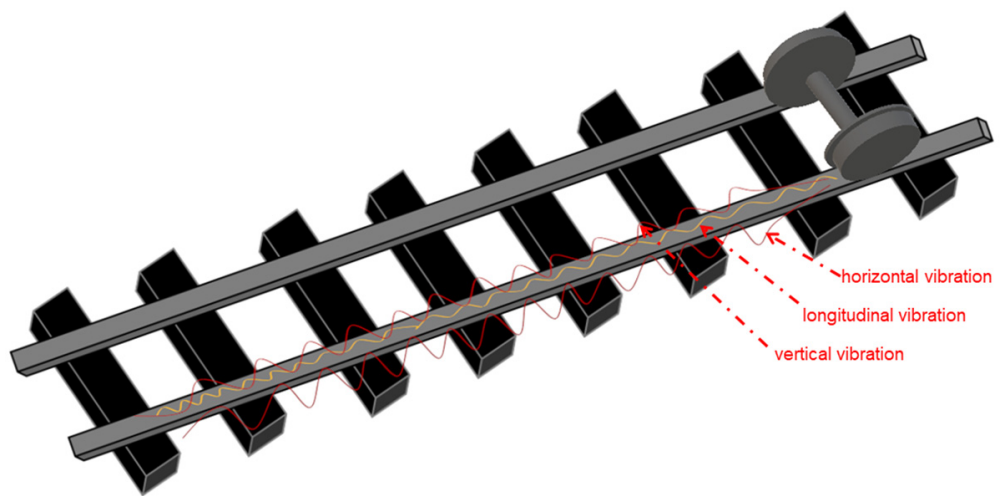

Fig. 1. Three axle vibration generated by the wheel-rail contact

The authors have conducted some preliminary research on application of vibration signals for analysis of driving properties of rail vehicles. For example, the paper [11] presents results of proposed metric calculated as inverse tangent function of current longitudinal and transverse accelerations.

\section{Research method}

The research was conducted on experimental rail track with typical level crossing devices. The aim of the research was analysis of possibilities of vibration employing for the trains traffic detection. During the research it was used as train simulator 2-axle bogie. The set of investigations have been conducted on the propagation of vibration in the track. The measurement system during the research have been depicted in Fig. 2.

The first stage of experiment was conducted on the experimental real size track. The track used was composed of two rails lying on wood sleepers joined by railpads. During the research the 3 -axle acceleration of vibration was recorded. The measuring system allowed synchronous recording signals that determined the correct analysis with respect to the time domain. 


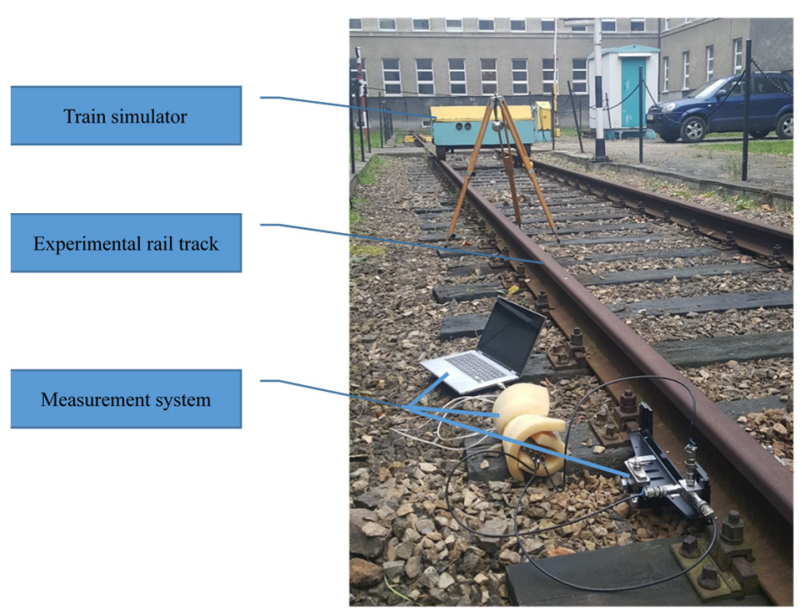

Fig. 2. Research setup

\section{Result}

The paper presents results of vibration registered during train simulator passage. Based on waveforms of the signals the local maximums values can be observed (Fig. 3). For the purpose of analysis of dynamical properties of the vibration the Fourier Transformation has been calculated. It allows to observe the frequency bands of the dominant vibration response (Fig. 3).
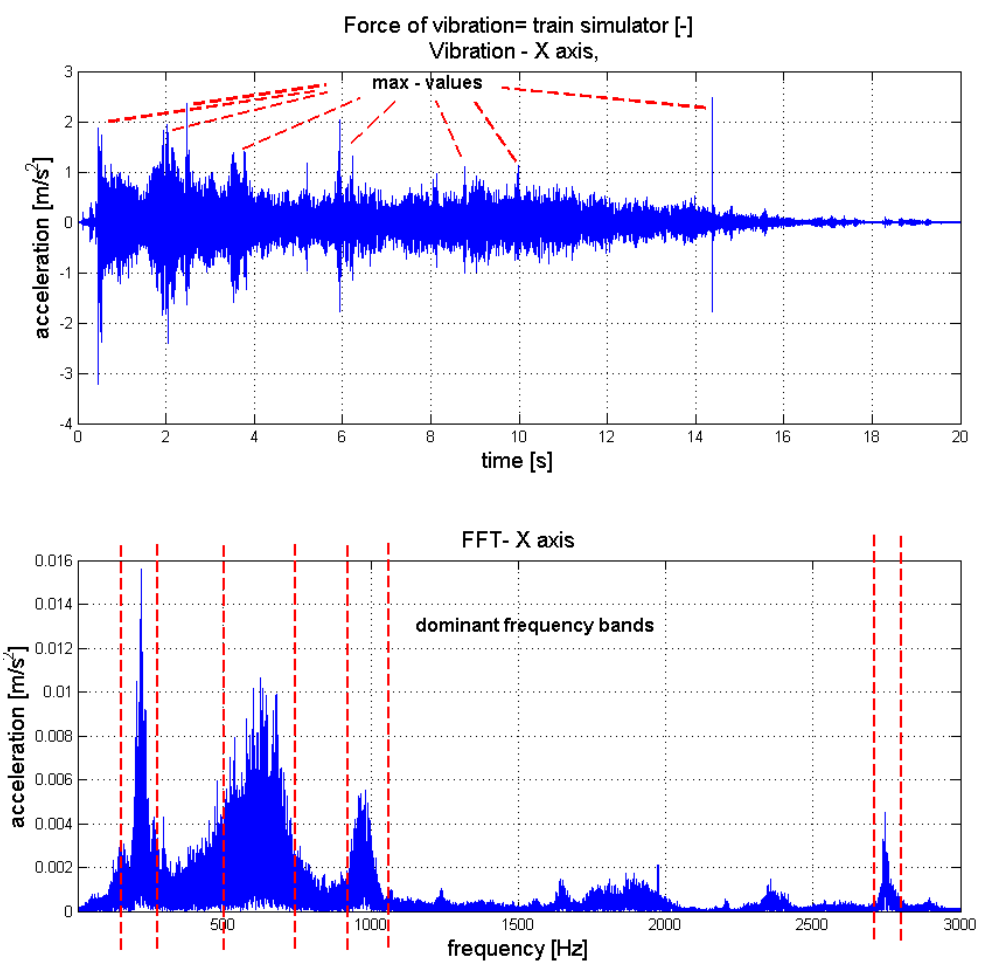

Fig. 3. Waveform and spectrum of longitudinal vibration generated by the train simulator passage

Due to properties of vibration propagation phenomena the paper presents also the results of horizontal and vertical vibration (Figs. 4, 5). 

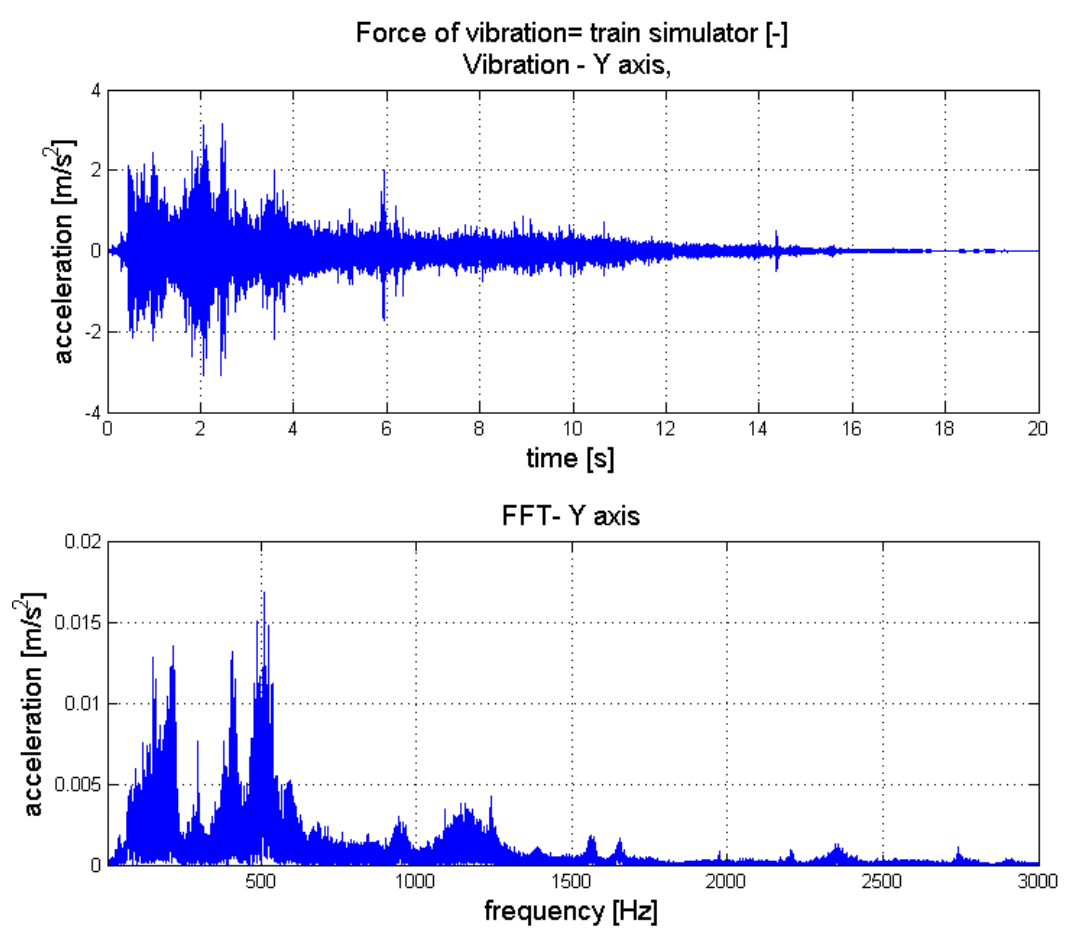

Fig. 4. Waveform and spectrum of horizontal vibration generated by the train simulator passage
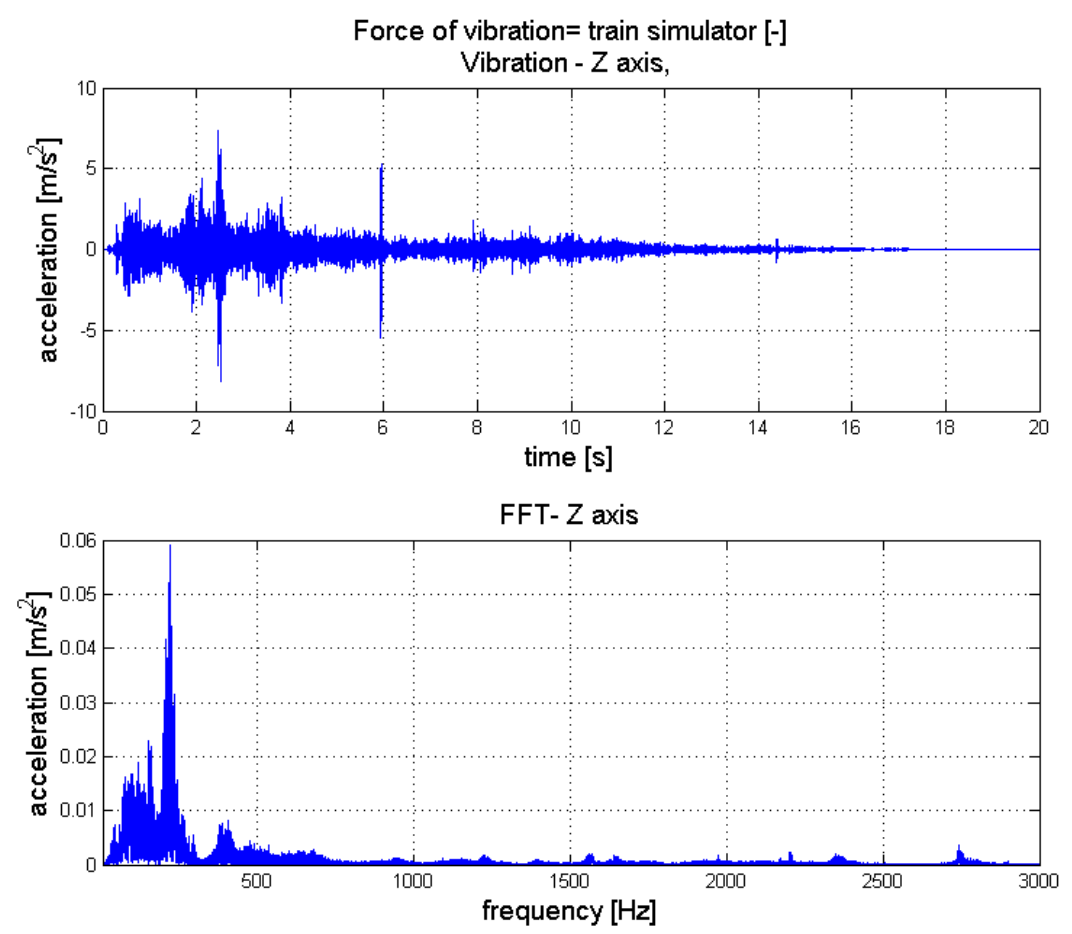

Fig. 5. Waveform and spectrum of vertical vibration generated by the train simulator passage

For the sake of the numerical analysis of magnitude of the vibration the basic statistics have been calculated. The comparison of these values has been presented in Table 1 and Fig. 6 . 
The results show differences in distribution of longitudinal, horizontal and vertical vibration waves components.

Table 1. Basic statistics of vibration signals

\begin{tabular}{|c|c|c|c|}
\hline \multirow{2}{*}{ Basic statistics } & \multicolumn{3}{|c|}{ Axis } \\
\cline { 2 - 4 } & $X$ & $Y$ & $Z$ \\
\hline min & $-3,231$ & $-3,103$ & $-8,179$ \\
\hline max & 2,471 & 3,170 & 7,329 \\
\hline mean & $-0,00118$ & $-0,00092$ & 0,00233 \\
\hline median & $-0,00042$ & $-0,00022$ & 0,00261 \\
\hline mode & 0,00017 & $-0,00130$ & 0,00379 \\
\hline std & 0,21461 & 0,26380 & 0,47920 \\
\hline range & 5,702 & 6,272 & 15,510 \\
\hline
\end{tabular}

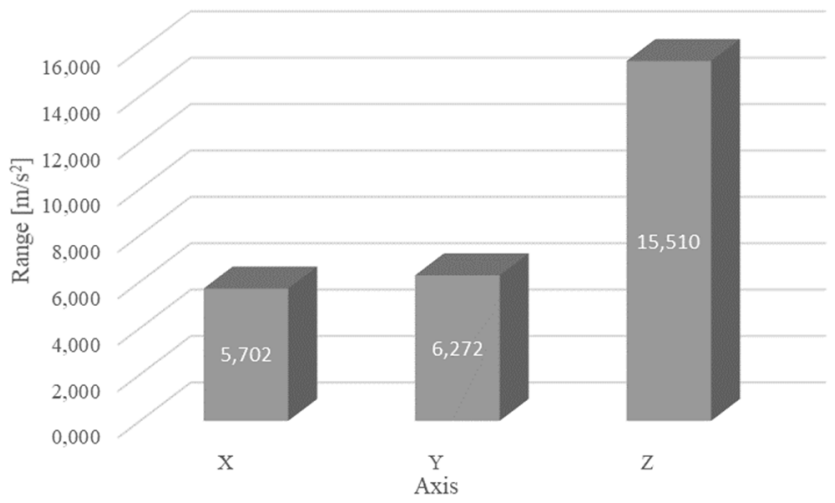

Fig. 6. Comparison of range of the vibration signals of three orthogonal axes

\section{Conclusions}

The paper presents results of preliminary research on vibration employed for the trains traffic control. The goal of the investigation was analysis of identification of train approaching detection based on vibration signal.

There are many approaches to transport safety testing, from risk-based approaches, through the assessment of safety systems to transport infrastructure and transport security systems, to organization verification and traffic control. The paper presents the conception of vibration employed information system. It also encourages open discussion on different innovative approaches.

\section{References}

[1] Lenné Michael G., et al. Driver behaviour at rail level crossings: Responses to flashing lights, traffic signals and stop signs in simulated rural driving. Applied Ergonomics, Vol. 42, Issue 4, 2011, p. $548-554$.

[2] Davey J., et al. The experiences and perceptions of heavy vehicle drivers and train drivers of dangers at railway level crossings. Accident Analysis and Prevention, Vol. 40, Issue 3, 2008, p. 1217-1222.

[3] Li-Sian T., Ferreira L., Wallace A. Measuring driver responses at railway level crossings. Accident Analysis and Prevention, Vol. 43, Issue 6, 2011, p. 2134-2141.

[4] Wei C., et al. A fiber Bragg grating sensor system for train axle counting. IEEE Sensors Journal, Vol. 10, Issue 12, 2010, p. 1905-1912.

[5] Matsumo M. The revolution of train control system in Japan, autonomous decentralized systems. International Symposium on Autonomous Decentralized Systems, 2005.

[6] Burdzik R., Nowak B., Młyńczak J., Deuszkiewicz P. Analysis of the detection and crossing signaling system in safety terms. Diagnostyka, Vol. 17, Issue 4, 2016, p. 65-72. 
[7] Burdzik R., Nowak B. Identification of the vibration environment of railway infrastructure. Procedia Engineering, Vol. 187, 2017, p. 556-561.

[8] Auersch L. Theoretical and experimental excitation force spectra for railway induced ground vibration: vehicle-track-soil interaction, irregularities and soil measurements. Vehicle System Dynamics, Vol. 48, Issue 2, 2010, p. 235-261.

[9] Krylov V. Spectra of low frequency ground vibrations generated by high speed trains on layered ground. Journal of Low Frequency Noise, Vibration and Active Control, Vol. 16, Issue 4, 1997, p. $257-70$.

[10] Picoux B., Le Houedec D. Diagnosis and prediction of vibration from railway trains. Soil Dynamics and Earthquake Engineering, Vol. 25, 2005, p. 905-921.

[11] Młyńczak J., Burdzik R., Celiński I. Research on Dynamics of Shunting Locomotive During Movement on Marshalling Yard by Using Prototype of Remote Control Unit, Dynamical Systems: Theoretical and Experimental Analysis. Springer International Publishing, 2016, p. 279-292. 